\title{
Groundwater artificial recharge solutions for integrated management of watersheds and aquifer systems under extreme drought scenarios
}

by

\author{
J.P. Lobo Ferreira, Catarina Diamantino and Maria José Henriques \\ Laboratório Nacional de Engenharia Civil, Av. do Brasil, 1700-066 Lisboa, \\ Portugal, e-mail: Iferreira@Inec.pt
}

\begin{abstract}
:
This paper addresses groundwater artificial recharge solutions for integrated management of watersheds and aquifer systems under extreme drought scenarios. Based on a lecture presented by Dr. JP Lobo Ferreira at UNESCO's International Year of Planet Earth (IYPE) Workshop held in Oslo, Norway, August 2009, the conceptual idea of Aquifer Storage and Recovery (ASR) is considered, in this paper, as one of the scientific based solutions towards scientific based mitigation measures to climate variability and change in many parts of the world.

In Portugal two European Union sponsored $6^{\text {th }}$ Framework Programme for Research Projects have been addressing this topic, namely GABARDINE Project on "Groundwater artificial recharge based on alternative sources of water: Advanced integrated technologies and management" (cf. http://www.Inec.pt/organizacao/dha/organization/dha/nas/estudos id/gabardine) and the Coordinated Action ASEMWATERNet, a "Multi-Stakeholder Platform for ASEM S\&T Cooperation on Sustainable Water Use" (cf. http://www.Inec.pt/organizacao/dha/nas/estudos id/asemwaternet and
\end{abstract} http://www.asemwaternet.org.pt).

This paper addresses selected achievements of those Projects.

\section{Introduction}

Pyne (1995) defined Artificial Storage and Recovery (ASR) as "the storage of water in a suitable aquifer through a well during times when water is available, and recovery of the water from the same well during times when it is needed".

The Australian ASR and Artificial Storage, Transport and Recovery (ASTR) Guideline (Dillon et al., 2006) advices nine guiding principles necessary to achieved best practices for ASR and ASTR. They are: Adopting a risk management approach, preventing irreparable damage, demonstrations and continuous learning, adopting a precautionary approach, establishing water quality requirements, rights of water bankers and recoverable volume, finite 
storage capacity of aquifers and interference effects between sites, highest valued use of resources and community and other stakeholder consultation.

Towards a sounder selection of the most appropriate method to build ARS facilities, several experiments have been carried out in the Portuguese Southern region of the Algarve. The values obtained for infiltration rates available on the multiple experimental facilities, depend not only on the hydraulic heads but also on the type of experiments and on the type of soils available regionally. The results gathered allowed the drawing of several original charts on infiltration rates that will be presented at the end of this paper.

In parallel a new method, called GABA-IFI, aiming preliminary identification of candidate areas for the installation of groundwater artificial recharge system was developed for ASEMWATERNet Coordination Action, at LNEC, based on based previous studies developed for five Portuguese Watershed Plans by Oliveira and Lobo-Ferreira (2002). This new method is described in http://www.asemwaternet.org.pt/pdf/events/GAB-IFI eng.pdf. It was applied both to Campina de Faro aquifer and to Querença-Silves aquifer, in the Algarve.

\section{Why do we need to consider droughts and ARS facilities? The example of Portugal}

A drought is a natural phenomenon in the Mediterranean region. It is not a fatality rather a recurrent situation requiring solutions and mitigation measures.

In Portugal the characterization of droughts is made since 1942 using precipitation data. Using the SPI-12 index (cf. Palmer, 1965) it is possible to say that since the agricultural year (September to August) of 1943/1944 there have been five years considered as drought in most of the country, being two years extreme droughts (cf. Domingos, 2006). An example of such characterizations can be seen in Figure 1. In this figure rows correspond to years (1969-2005) and columns correspond to districts from Northern Portuguese districts (on the left side) to Southern districts (in the right side). One may easily see in this SPI12 index table, computed for all Portuguese mainland districts (i.e. not for the Portuguese Azores and Madeira archipelagos) a sequence of blue lines (wet years) flowed by a frightening sequence of red lines (dry years), that seams to become more solid as time proceeds, and also more compact along the districts from North to South. Some thing has to be done on adaptation measures to this reality. It is time now to proceed with scientific based appropriate methodologies to avoid recurrent scarcity.

\section{Artificial recharge experiments in the Algarve}

Following what was mentioned in the Introduction, the main objectives of Gabardine Project in the Algarve were: (1) to identify alternative water sources and study the economic and environmental feasibility of its use in semi-arid areas, in the context of an integrated water resources management, (2) to study the aquifers as a main water source for both seasonal and long term storage of these alternative water sources and (3) to improve knowledge about possible 
methods to introduce these water sources in the aquifer, namely through artificial recharge.

Alternative water sources for groundwater artificial recharge may include the superficial runoff surplus produced during flash flood events, treated urban wastewater, desalinate water surplus or water import.

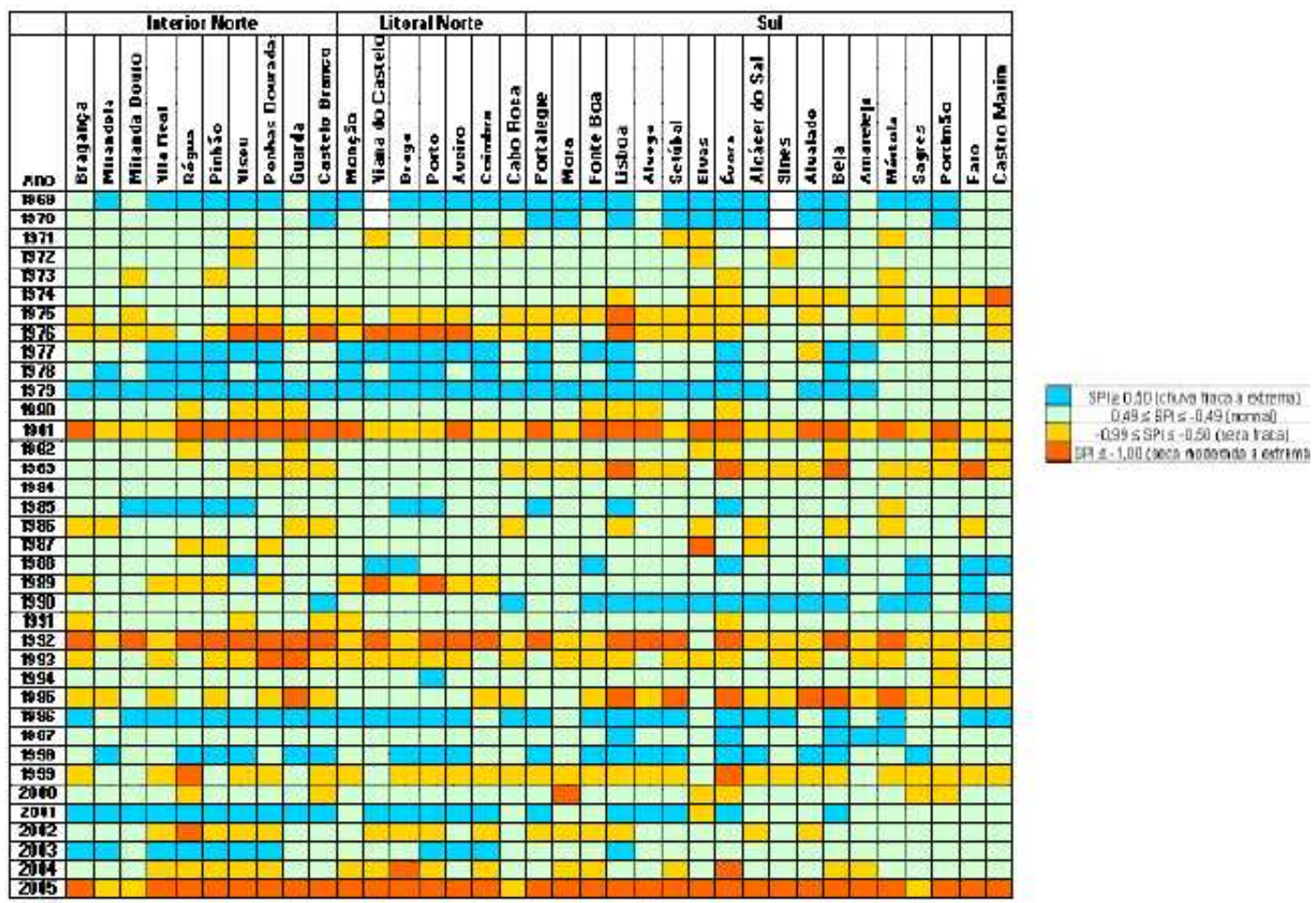

Figure 1 - SPI-12 values computed for selected municipalities (columns) from 1969-2005 for the Northern coastal zone and interior regions of Portugal as well as for the Southern region

The development of this study approached several issues related to the subject like: precipitation rate analysis, both water and recharge balance, identification of the potential alternative water sources intended to recharge the aquifer and assessment of existing technologies for its use, development of tools aimed for managing groundwater recourses considering artificial recharge, assessment of aquifer vulnerability and characterization of the unsaturated zone. Several artificial recharge devices have been developed and implemented in Gabardine Project.

Regarding Campina de Faro aquifer case study in the Algarve, the main goal was to optimize groundwater rehabilitation through implementation of artificial recharge, minimizing the effects of diffuse pollution caused by agricultural practices. This goal aimed the assessment in the Portuguese study area of problems resulting from the application of these practices. Today they are well documented in terms of groundwater quality. The study area was designated as a vulnerable area concerning nitrate concentration by the application in Portugal of the Nitrate Directive (in 2004). Together with the "good quality status" referred by the Water Framework Directive, these are the main reasons for the implementation of infrastructures aiming the improvement of groundwater quality in a section of this aquifer allowing, on the other hand, increasing groundwater availability with good quality in the Algarve region. 
The Project improved scientific knowledge of several methodologies aimed not only to improve groundwater quality but also allowing subterranean storage of water with good quality in wet year periods of major availability and during events of heavy rainfall.

Multiple artificial recharge experiments were accomplished in the Portuguese case study area during the second year of the Project by Diamantino et al. (2007). Figure 2, presenting a set of selected pictures, show an example. The purpose of the experiments was to assess and quantify the effectiveness and applicability of the different groundwater artificial recharge methodologies, in a way that the achieved results can contribute to the development of the Gabardine Decision Support System (GDSS).

Complementarily, it was included a preliminary development of an optimization model that merges restrictions and parameters for the objective function. Its future application will allow selecting more adequate techniques considering the maximization of the improvement of water quality and total cost minimization.

\section{Artificial recharge tests in infiltration basins}

The objective of the AR was the assessment of infiltration rates in the very permeable yellow sands and to assess the unsaturated zone, and saturate zone transport parameters with a tracer test. To accomplish this purpose Areal Gordo AR Basins 1, 2 and 3 (Figure 2 and Figure 3 ) have been constructed for in situ infiltration and tracer test experiences. Besides, laboratory soil-column tests were performed in soil samples collected at the bottom of the basin. Areal Gordo AR Basin 2 had an area of $61 \mathrm{~m}^{2}$. The bottom was excavated up to the third layer of yellow sandy soils at approximately 8 meters depth. The source of water for this infiltration test comes from a nearby well opened in the confined aquifer. To fulfil the objective of measuring the infiltration rate capacity, the water level in the basin was maintained constant (with a water column of approximately $90 \mathrm{~cm}$ ) for a period of 3 days, and the infiltration rate was calculated by dividing the volume of water added by the basin area. At that time, the piezometric level and the groundwater quality parameters have been continuously recorded at the $6 \mathrm{~m}$ far LNEC4 well. The arrival to this well was 70 hours. This allowed estimating the permeability of this sandy layer as $0.21 \mathrm{~m} / \mathrm{d}$, considering the distance of 8 meters between the bottom of the infiltration pond and the well (i.e. up to $1.5 \mathrm{~m}$ in the vadose zone $+6.5 \mathrm{~m}$ distance in the aquifer).

\section{Artificial recharge using a large diameter well}

In the case study area of Campina de Faro a large amount of $5.0 \mathrm{~m}$ diameter wells equipped with a waterwheel are common, the so called "noras" (Figure 4). Some of them are still used for agricultural irrigation or even domestic consumption. In Areal Gordo an injection test was performed in one of those wells with the objective of assessing if they could be an effective infrastructures to be used, as already available facilities for AR. Also foreseen was the assessment of the infiltration rate vs. the recharging depth of water column, ranging from the surface to water table depth. Besides recording the level inside the large diameter well the effect of the recharge in the regional 
water level was monitored in the nearby LNEC5 monitoring well. This well allowed assessing a first approach to the groundwater hydraulic conductivity and some transport parameters. The input water discharge from a close deep well was controlled during the injection periods. The main characteristics of this large diameter well are presented hereinafter: area at the bottom of the "nora" with a diameter of $5 \mathrm{~m}=19.625 \mathrm{~m}$; depth to water table at the beginning of the first test=19 m; available storage volume at the "nora" for the test=373 $\mathrm{m}^{3}$; total well depth=24 m. The monitoring equipment used was the following: multiparametric water sensors for continuous monitoring installed in the "nora" and LNEC5 well; from the discharge well a flow meter was installed for continuously record the discharge water volume.

Three injection tests were developed during March, 2007. A maximum value was assessed when the water level at the "nora" stabilized near the surface (at $1.5 \mathrm{~m}$ depth) allowing the recharge water input of $20 \mathrm{~m}^{3} / \mathrm{h}$ to be incorporated in the aquifer. The values vary with the water level inside the "nora" ranging from $0.25 \mathrm{~m} / \mathrm{d}-1.18 \mathrm{~m} / \mathrm{d}$ to a maximum value of $24.5 \mathrm{~m} / \mathrm{d}$, respectively for the 1st, 2nd and 3rd test (Figure 5). As expected, it was concluded that increments in the infiltration rate are strongly connected to the increase in the water column inside the well

\section{Artificial recharge using a medium diameter well}

A one day injection test was performed in an experimental medium diameter well of $0.5 \mathrm{~m}$, located in Areal Gordo, and called LNEC6. The objective of this test was to determine the infiltration capacity and to compare it to the one assessed for the $5 \mathrm{~m}$ large diameter "nora". The injection test was performed during 4 hours and the depth to water table was recorded during the test. The input water discharge from a close deep well was controlled during the injection periods. Two injection discharges were considered, one to fill up the well and the other necessary to stabilize the water level: Qi_ascend $=20 \mathrm{~m}^{3} / \mathrm{h}$ and Qi_descend $=2.2 \mathrm{~m}^{3} / \mathrm{h}$. The main characteristics of LNEC6 well, opened in the unconfined sandy aquifer, are the following: section area (diameter 0.5 $\mathrm{m})=0.196 \mathrm{~m}^{2}$; depth to water table $=18.9 \mathrm{~m}$; available storage volume $=3.7 \mathrm{~m}^{3}$; total well depth $=28 \mathrm{~m}$. The monitoring equipment used was the same as in the previous injection test. The depth to the water table recorded in LNEC6 is plotted in Figure 6 as well as the two injection periods (4 hours total time duration). The infiltration rate was calculated by the change in the water level after the stop of the injection and during the necessary time interval to achieve the initial head, before the injection test (i.e. $7.4 \mathrm{~m}$ of water level variation during 0.6 days $=11.5 \mathrm{~m} /$ day of infiltration rate) .

\section{Artificial recharge experiments in river bed infiltration basins}

In Rio Seco river bed, two $100 \mathrm{~m}^{2}(20 \mathrm{~m}(\mathrm{H}) \times 5 \mathrm{~m}(\mathrm{~W}) \times 5 \mathrm{~m}(\mathrm{D}))$ infiltration basins were constructed and filled in with clean gravels for AR tests (Figure 7). The main objectives of the experiment were to assess the effectiveness of this type of AR structures for surface water infiltration, including the computation of groundwater recharges rates and evaluating groundwater mass transport parameters in unconfined aquifer via the monitoring of a breakthrough tracer curve. Two concrete sections were constructed and two pneumatic gauges for 
river water levels control were installed, upstream and downstream of the infiltration basins, during January, 2007, in order to measure the river discharge upstream and downstream the AR infiltration basins. Tracer tests have been performed during May, 2007 (Figure 8 and Figure 9).
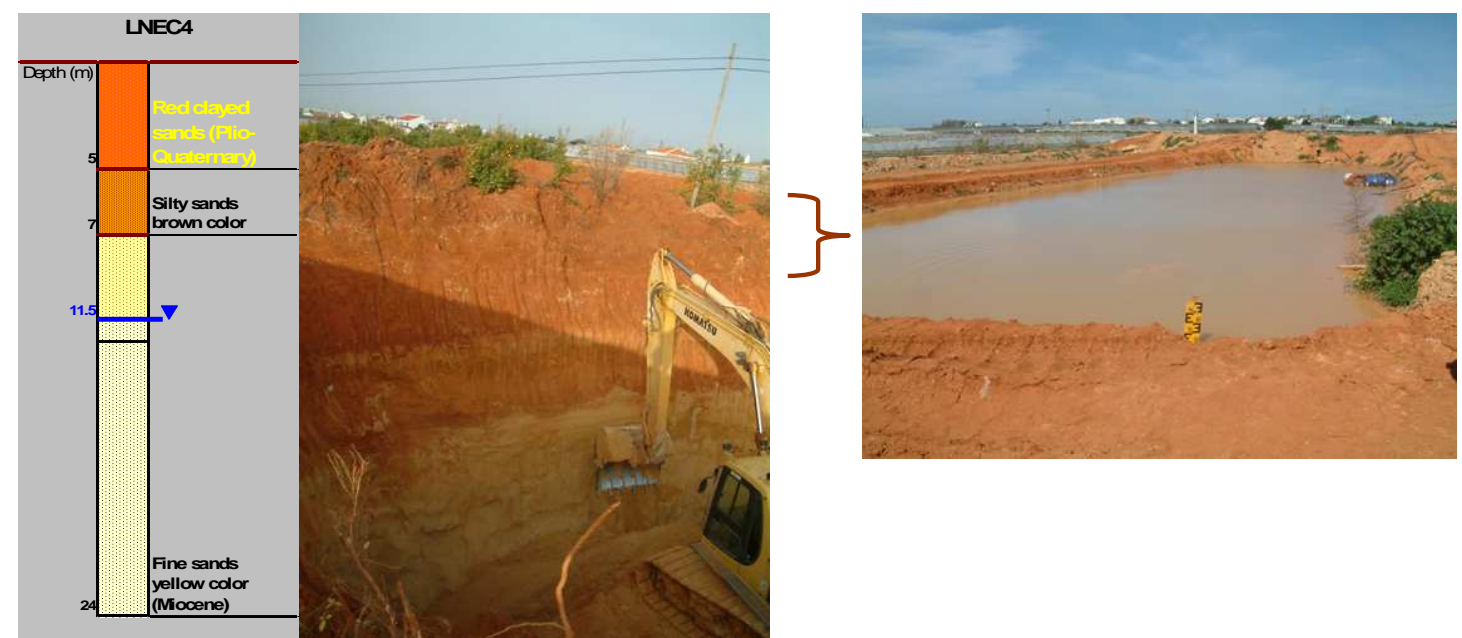

Figure 2 -Vertical profile of lithological materials in Areal Gordo (at right) and LNEC4 well lithological column and, infiltration basin in the first layer (at left)
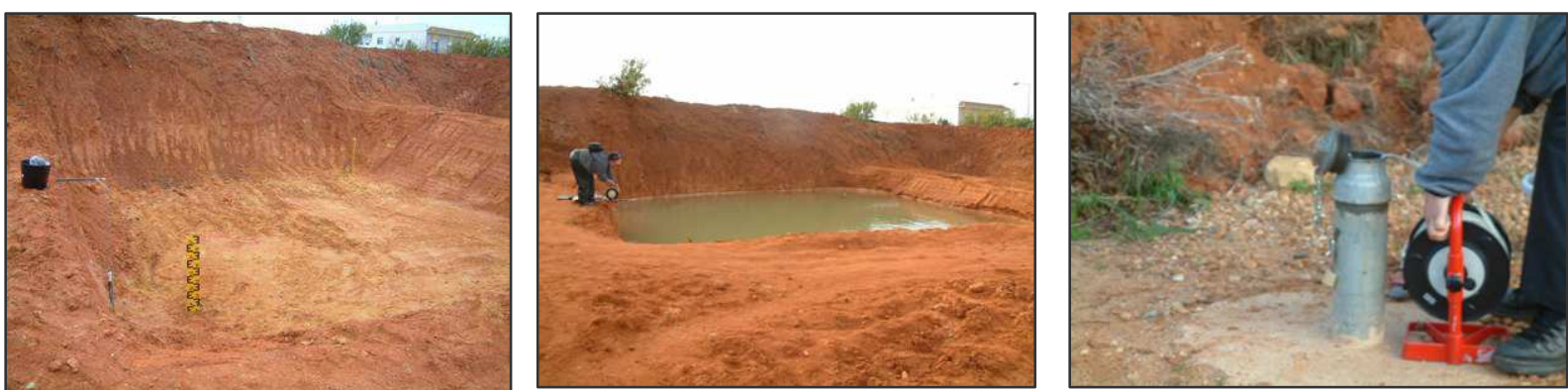

Figure 3 - Infiltration basin in the second layer and monitoring equipment used for the infiltration test
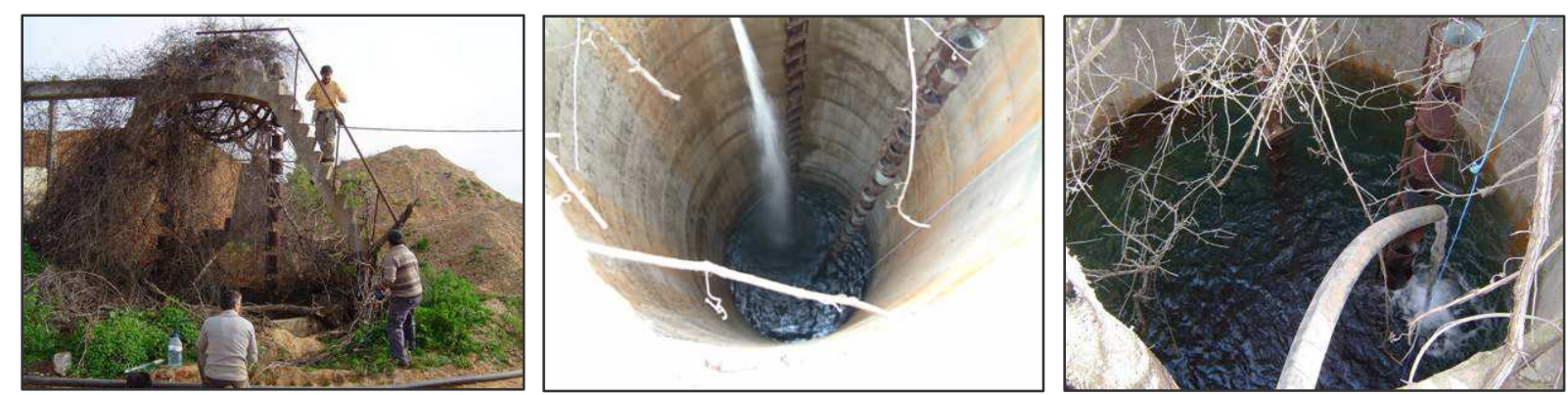

Figure 4-Injection test developed in the "nora": water levels at the beginning and at the end of the test 


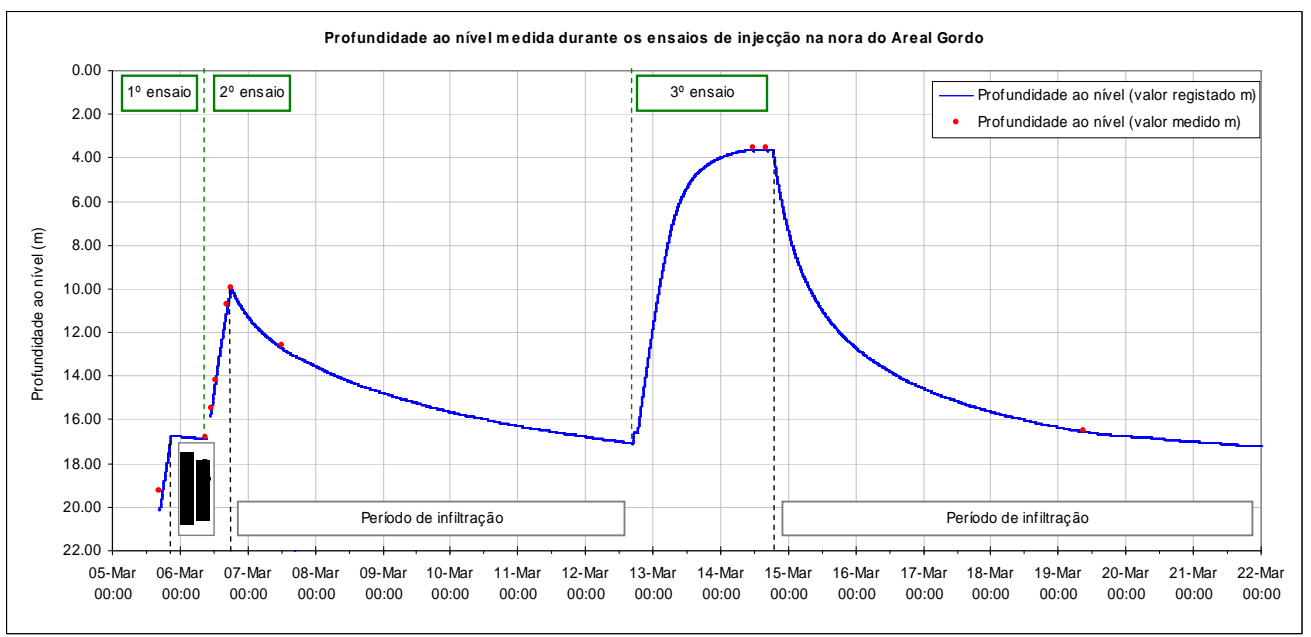

Figure 5 - Depth to the water table automatically recorded and manually measured during the injection tests performed in the "nora"

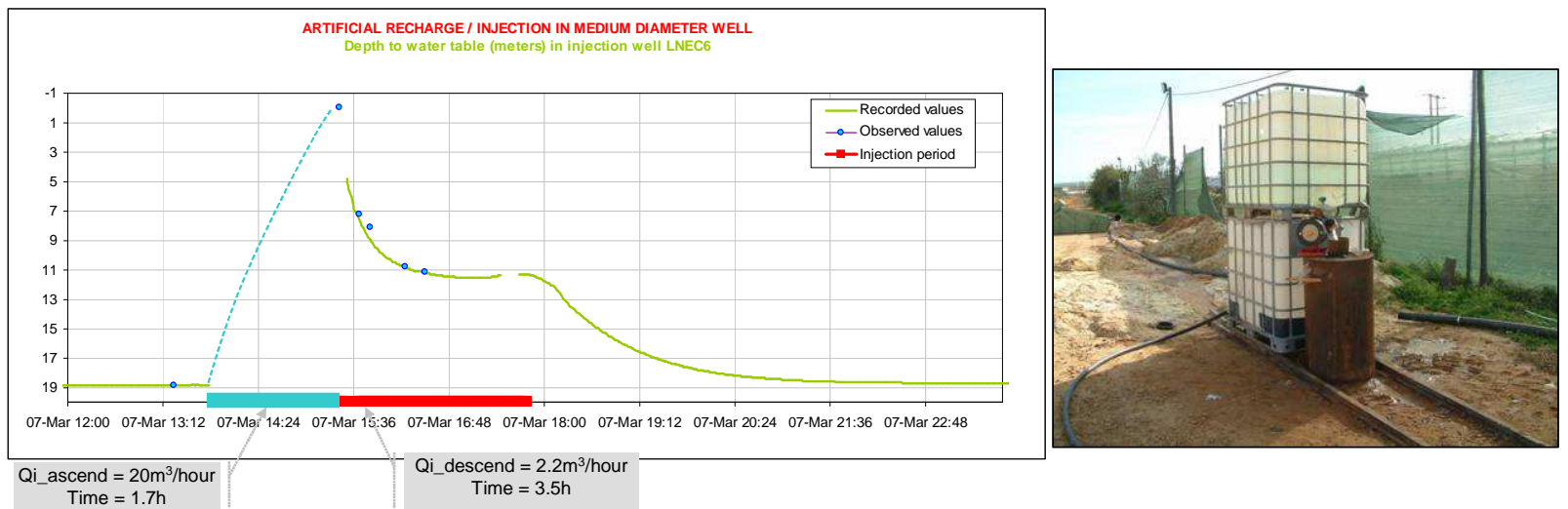

Figure 6 - Depth to the water table automatically recorded and manually measured in LNEC6 (medium diameter well) during the injection test

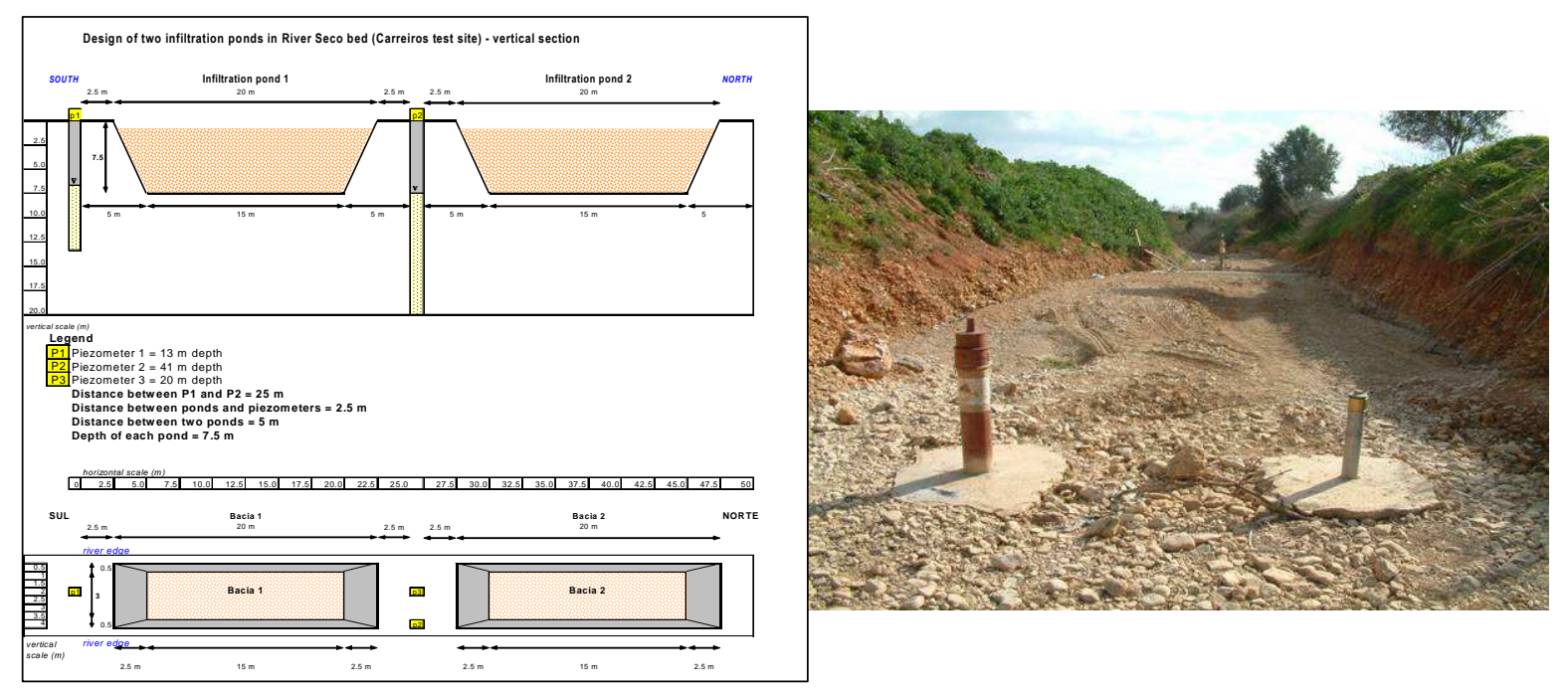

Figure 7 - Design configuration of the two infiltration basins in the river bed of rio Seco (Carreiros)

Results of the groundwater quality and quantity assessment recorded in the monitoring wells during the rainy months of November and December 2006, 
when surface runoff infiltrates in basins, show $\mathrm{NO}_{3}{ }^{-}$concentrations strongly decreasing the same period and tend to get closer to the $\mathrm{NO}_{3}{ }^{-}$quality value of the river water (Figure 10).

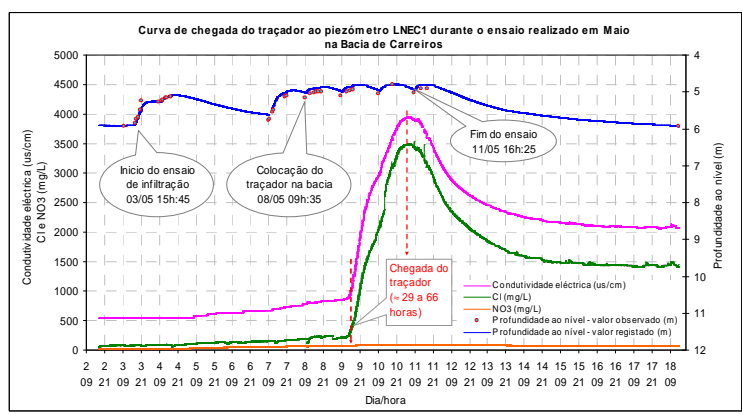

Figure 8 - Breakthrough tracer experiment curves at Rio Seco infiltration basin (Carreiros)

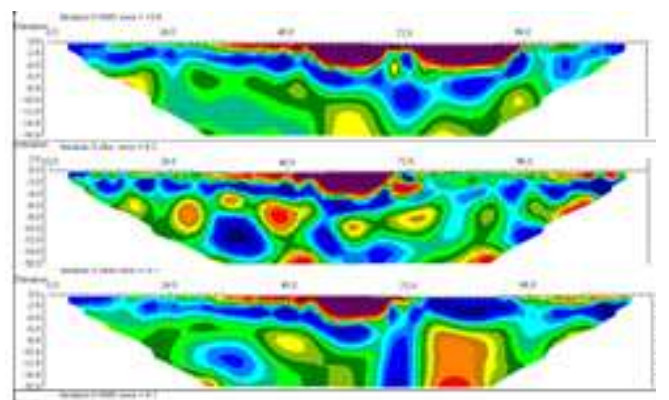

Figure 9 - Electric resistivity models obtained before, during and after the tracer test at the infiltration basin in Rio Seco, Carreiros (Mota et al., 2008)

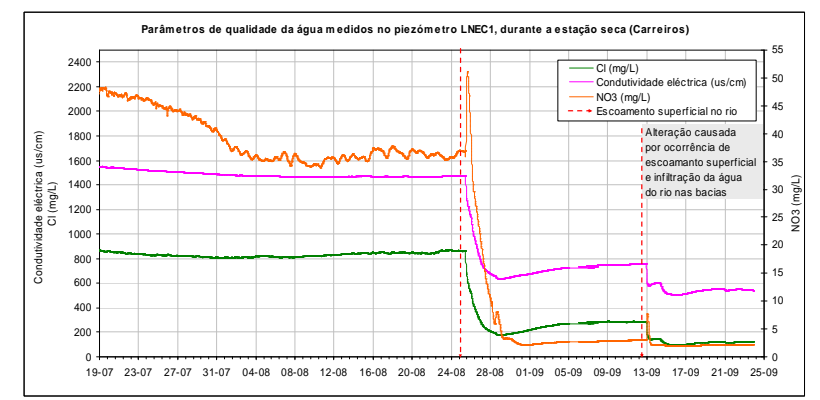

Figure 10 - Variation of the water quality in Campina de Faro unconfined aquifer, after runoff events in Rio Seco, monitored in LNEC 1 piezometer $2.5 \mathrm{~m}$ downstream of the infiltration basin

This is a remarkable fact, and of paramount relevance regarding the achievements of artificial recharge experiments towards the rehabilitation of the polluted unconfined aquifer, confirmed by LNEC 1 piezometer $2.5 \mathrm{~m}$ downstream of the infiltration basin.

\section{Conclusions}

As main conclusion, we may state that artificial recharge may be seen as one good solution aiming a scientific based adaptation to climate change or climate variability conditions in the near future. This technology allows the use 
of surplus water in wet years or so that extra supply water may be available later in dries years. As we have clearly shown in this chapter for Campina de Faro, Portugal, other uses can be aimed at artificial recharge facilities, e.g. for cleaning polluted aquifer. So, the solutions proposed are worthy to be considered in implementing integrated water resource management plans, being part of a variety of solutions to minimize the water scarcity, for instance in the Algarve during severe drought situation.

Several in situ artificial recharge experiments and laboratory tests were performed in the framework of the Gabardine Project for a selected area of the Campina de Faro aquifer system. The comparison of different lithological materials in situ and in the lab, and the assessment of artificial recharge efficiency allowed data gathering regarding performances (on rates of infiltrations) and the adequacies of the different techniques for different geological layers (Figure 11). The in situ experiences showed very favourable rates of infiltration in yellow sands, especially in the large diameter well ("nora") experiment, when infiltration rates were as high as $24 \mathrm{~m} /$ day. In the case of the "nora" a function of the infiltration rate vs. the water column depth in the "nora" was computed.

The aim of all these experiments was to improve the knowledge on real case studies application of different $A R$ methodologies to assess the parameters needed to develop optimization models. The model may incorporate restrictions and parameters of the objective function that values evaluated in the experiments, described above. The results presented in this chapter allow the selection of most appropriate AR techniques aiming the maximization of groundwater quality improvement, while minimizing the cost.
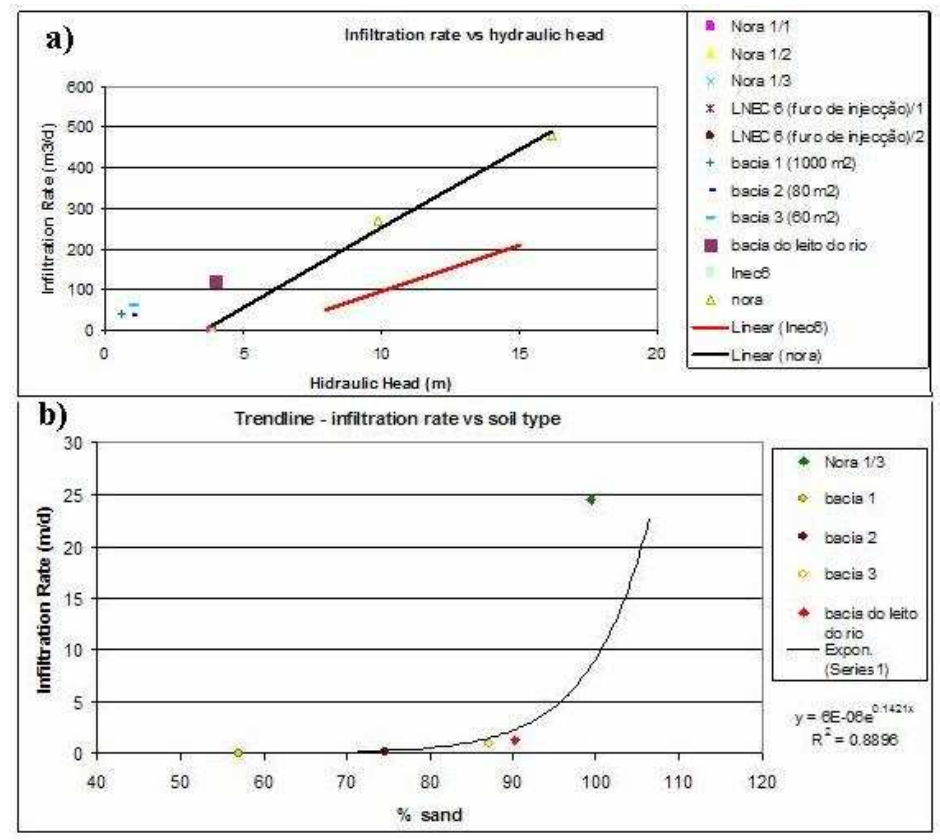

Figure 11 - a) Infiltration rates vs. the type of technology used (infiltration basins in the field or in river bed and, large and medium diameter recharge wells); b) Infiltration rates vs. the type of soil available in the Algarve at Campina de Faro and Rio Seco 


\section{ACKNOWLEGMENTS}

- $\quad 6^{\text {th }}$ European Union Framework Programme Project GABARDINE "Groundwater artificial recharge based on alternative sources of water: advanced integrated technologies and management".

- $\quad 6^{\text {th }}$ European Union Framework Programme INCO-CT2005-510897 Coordination Action ASEMWATERnet "Multi-Stakeholder Platform for ASEM S\&T Cooperation on Sustainable Water Use".

- The Portuguese Fundação para a Ciência e a Tecnologia (FCT) for financing Catarina Diamantino PhD. at LNEC. The Dissertation was completed February 2009, and delivered to Lisbon University September, 11, 2009.

\section{REFERENCES}

- Diamantino C., Lobo Ferreira, J.P., Leitão T. (2007) - "Artificial aquifer recharge experiments in the Portuguese Campina de Faro Case-Study area". In Proceedings XXXV IAH Congress, Groundwater and Ecosystems, Ribeiro, L., Chambel, A., Condesso de Melo, M.T. Eds, 17 a 21 de Setembro de 2007, Lisboa, 10 pp.

- Dillon, P. e Molloy, R. (2006) - "Technical Guidance for ASR - Developing Aquifer Storage and Recovery (ASR) Opportunities in Melbourne". CSIRO Land and Water Science Report 4/06, Australia, CSIRO Land and Water.

- Domingos, S. I. S. (2006) - "Análise do Índice de Seca Standardized Precipitation Índex (SPI) em Portugal Continental e Sua Comparação com o Palmer Drought Severity Index (PDSI)". Tese de licenciatura em Meteorologia, Oceanografia e Geofísica Interna - variante Meteorologia. Lisboa, Faculdade de Ciências - Universidade de Lisboa.

- Mota, R.; Monteiro dos Santos, F.; Diamantino, C.; Lobo Ferreira, J.P. (2008) "Evolução temporal da resistividade eléctrica aplicada a estudos ambientais e hidrogeológicos". XI Congresso Nacional de Geotecnia. 7 a 11 de Abril de 2008, Coimbra, 10 pp.

- Oliveira, L. (2007) - "Soluções para uma gestão adequada de bacias hidrográficas e de sistemas aquíferos, em cenários de escassez hídrica extrema. Aplicação ao sistema aquífero Querença-Silves (Algarve) no âmbito da Acção de Coordenação ASEMWaternet". IST, Mestrado em Engenharia do Ambiente, $102 \mathrm{pp}$.

- Oliveira, M.M. e Lobo Ferreira, J.P. (2002) - "Proposta de uma Metodologia para a Definição de Áreas de Infiltração Máxima". Artigo para o Vol.23 no1 da Revista "Recursos Hídricos". Lisboa, Associação Portuguesa dos Recursos Hídricos. pp. 63-74.

- Palmer, W. C. (1965) - "Meteorological Drought". Paper no 45. Washington D.C., Weather Bureau Research.

- Pyne, R.D.G. (1995) - "Groundwater Recharge and Wells: A Guide to Aquifer Storage Recovery". Boca Raton, Lewis Publishers. 